\title{
Teaching Electronics for non Electrical Engineers Using Blended Learning and Experiential Learning
}

\author{
Mohamed H. Bakr \\ McMaster University, Hamilton, Ontario, Canada
}

\begin{abstract}
I present in this paper overview of an experiment that was carried out at McMaster University, Canada, on teaching electronics for non electrical engineers. A combination of experiential learning and blended learning was used at an introductory electronics course. The initial results show improvement in the way students rated both the instructor and the course as a whole and in the way they understood the subject and how it relates to real life. I discuss different aspects of this work and present recommendations for improvement
\end{abstract} Casting;

Keywords-Experiential Learning, Blended Learning, Lecture

\section{INTRODUCTION}

Experiential Learning (EL) is a great tool for teaching engineering concepts [1]. In this approach, students learn through real-life experiments the different underlying concepts. EL requires students to fill in the gaps in their knowledge on their own and achieve results using their acquired experiences. These experiments may not yield a successful result from the first round. An iterative process may be applied to allow students to refine their experiments towards a successful result. Studies show that EL results in a better learning experience for students than traditional teaching approaches where the professor would teach all the bases of the subject.

Blended Learning (BL) [2] is another learning approach that attempts to make a better use of the classroom time. This approach recognizes that the class time is very precious to be spent in explaining lengthy mathematical derivations or other materials that students can read on their own. Using BL, the class time is dedicated to group discussions, solution of interesting design problems, real life applications, and quizzes that raise interesting questions. All or part of the theoretical content of the course is delivered online in the form of video clips (on YouTube for example). Students are asked to watch these videos before coming to class.

Electronics [3] is a subject that finds many applications in different disciplines. Electrical engineering students study this subject in detail as a core subject within their discipline. Mechanical engineering students, for example, need to study electronics to understand how different types of motors are being controlled. Mechatronic students study electronics to understand how to control robotic machines. Biomedical students need to study electronics to understand the different instrumentation and signal sampling approaches. Other engineering disciplines require some degree of understanding of electronics to enable using of different types of sensors.

The problem, however, is that many of the non electrical engineering students do not like to cover electronics courses. Many of them believe that this is not part of their required study and consider the subject useless over the long run. It was thus always difficult to engage non electrical engineering students and motivate them to learn and enjoy this interesting subject.

I report in this work on an experiment in teaching electronics for non electrical engineers. The experiment combined both experiential learning and blended learning approaches. All lectures were posted to students online before the class time. The class time was fully dedicated to discussions, solving interesting problems, real-life problems, and inspiring quizzes. The experiential part was included through a number of components. First, four hands-on experiments that address different parts of the course were carried out by students. A term-long project was also used to motivate students to understand how different electronic circuits are designed and simulated. In this project, students were asked to design using a simulator (Multisim) an electronic circuit that implements a specific functionality and uses only components that are covered within this course. An actual hardware implementation of the circuit was considered a bonus.

This paper starts by describing the elements of the experiment in Section II. The results are listed in Section III. Finally, the conclusions and recommendations are given in Section IV.

\section{EXPERIMENT DESCRIPTION}

This experiment was conducted in the winter term of 2015 in the engineering course ENG 3N03. The class had 52 students all in one section. The class is comprised mainly of mechanical and mechatronic students. The course format included 2 lectures per week and one tutorial. This course have one laboratory session every two weeks. The students conducted overall 4 hardware experiments that cover many of the concepts discussed within this course. 


\section{A. The Beginning}

Students were informed at the very first lecture that they are a part of an experiment in engineering education. They were informed that there were be no classical classroom teaching and that all lectures will be posted online by 5:00 pm, the day before the class. They were encouraged to watch the videos online to be able to catch up with the examples presented in class. The students were also informed that $10 \%$ of their mark depends on a design of an electronic circuit that makes use of the components discussed within this course. They were asked to form themselves into groups of 3-5 students and to come up with a proposal. The students collected their term-work marks from 5 quizzes (worth 10\%), 2 midterm examinations (each worth $10 \%$ ), four laboratory experiments (10\%), and a project (10\%). The final examination is worth $50 \%$ of the total course grade. The course marks were intentionally spread over different aspects to allow students to recover if they had a bad mark in one of these components.

\section{B. Experiential Learning}

Throughout this course, students study different electronic components including diodes, Zener diodes, operational amplifiers, BJT transistors, MOSFET transistors, and JFET transistors. They learn the theory of operation of these devices and they are taught to solve simple circuits containing one or more of these components in addition to capacitors, inductors, and resistors.

To enforce the experiential learning aspect of this course, students were asked to design a circuit and possibly assemble it that achieve a certain functionality. They were asked to form groups of 3-5 students and work together towards learning the theory of operations of these circuits and how they can be designed. Every group was asked to present their proposal through a YouTube video that was rated by the rest of the class. All these projects were limited to the components taught in this course. Students were not allowed to use available complex chips models that have thousands of builtin components.

The students suggested many circuits that included AM modulators and demodulators, FM modulators and demodulators, electric waveform generators, signal jammers, etc. The free software Multisim [4] was used to design these circuits and check their output.

Towards the end of the semester, students were asked to present their projects and explain in a clear way the design procedure they followed. Some groups were encouraged to assemble these circuits into actual hardware by offering them bonus marks.

\section{Blended Learning}

Lectures were taped using the iTunes App DoodleCast Pro. The slides of every lecture were saved as .JPEG files and then imported into the lecture cast. The DoodleCast App allows the students to see a "white board" on which the instructor can show illustrative figures and write comments. It allows the voice of the instructor also to be heard throughout the lecture

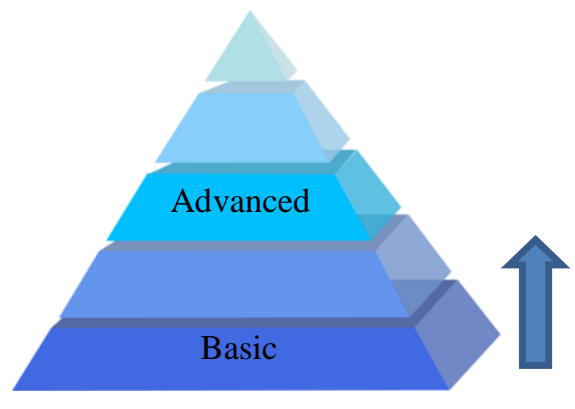

Fig. 1. Course philosophy; at students are learning basic theoretical details and at a higher level students are carrying out advanced projects [5].

cast. This App does not, however, allow the instructor to show his face on the side of the slides as some other more expensive lecture casting software do.

The lectures were posted the day before the lecture is conducted. Students were asked to watch these videos before coming to the classroom. The instructor stressed in the very first lecture the importance of watching the lectures on time. Students were shown results from previous experiments that show strong correlation between achieving good results and timely watching of the online material.

The instructor effectively converted all three in-class sessions to tutorials. Interesting examples and discussions were conducted in these sessions. Students were encouraged to participate in the discussions and they were rewarded with candy. Also, to help student keep on track with watching their videos, a weekly quiz that cover the last three posted lectures was conducted. These quizzes were given $10 \%$ of the total course weight. The five quizzes with the best marks were recorded for each student.

Fig. 1 illustrates the general philosophy used in this course. At the lower level of the knowledge pyramid, the instructor taught students the basic concepts during casted lectures and tutorials. At a high level of the pyramid, students are assumed to have already sufficient knowledge to carry out an advanced project that only a practicing engineering would be able to do. They had to acquire the necessary knowledge through reading research papers, online materials, and through the interaction with the instructor [5].

\section{Implementation}

To encourage students to watch the online videos on time, a weekly quiz with a value of $1 \%$ was carried out. This quiz covered only materials included in the last 3 lectures. Also, because the blended learning approach requires more time from the students ( 3 lectures online and 3 tutorials per week), from time to time, the instructor would replace a lecture session with office hours time. This allows students who have questions in the covered material to ask them and at the same time it releases some time for other students. 


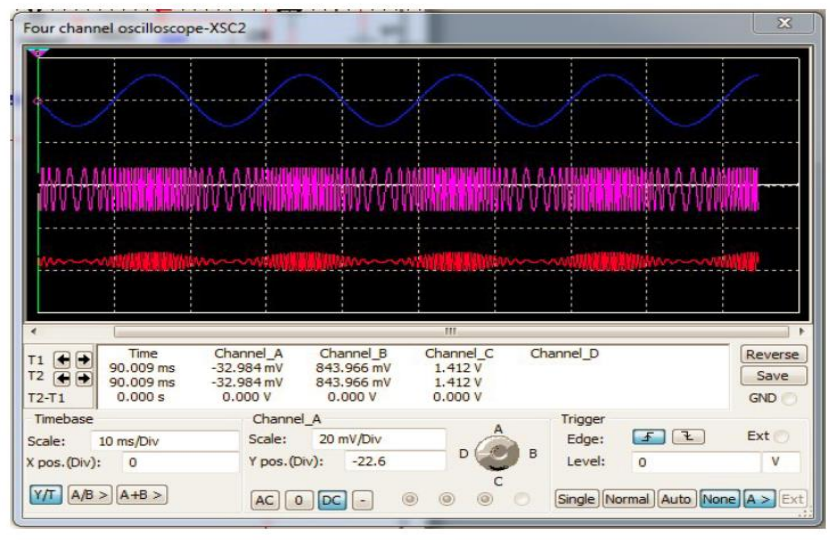

Fig.2. The output from an FM demodulator circuit designed by one of the groups.

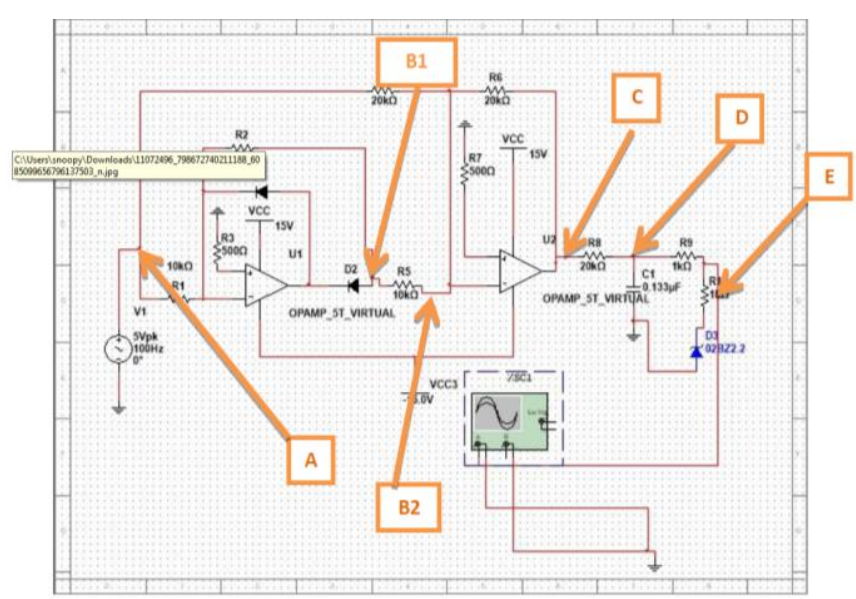

Fig. 3. A screen capture of one of the circuits designed by the students' groups. Only components covered within the scope of the course were allowed.

To help students who missed to watch the online video, the instructor would start the session by giving a 5-minutes summary of the theory that was covered in the video. This also helped students who watched the video to recall the important points.

A problem that is faced often in engineering courses is how to synchronize lectures and laboratory sessions. Very often students have to carry out laboratory experiments with the corresponding material not yet covered in lectures. The instructor changed the course content to fully synchronize lectures and laboratory experiments. The students thus gain maximum benefit by carrying out actual measurements that verify the theoretical and applied content covered in online videos and face-to-face sessions.

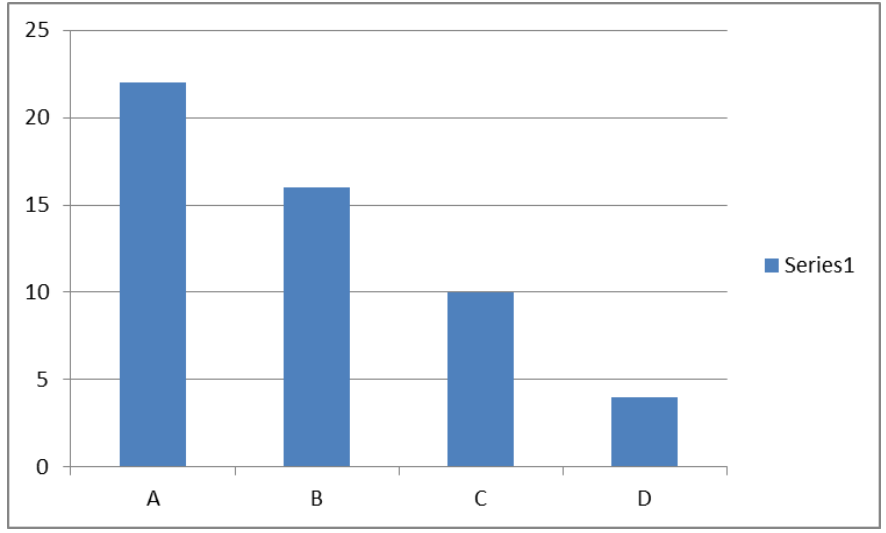

Fig. 4. The final result of the class.

\section{RESULTS}

Over $90 \%$ of the students were able to successfully finish their projects. Some groups were able to construct a hardware implementation of their projects. The structures designed by two groups of students are shown in Figs. 2 and 3. In Fig. 2, the modulating signal of an FM signal is recovered using a circuit that utilizes transistors, resistors, and capacitors only. Fig. 3 shows the structure of a rectification circuit. This circuit uses only OpAmps, diodes, resistors, and capacitors. All of these components were covered within this course.

The final result of this course is shown in Fig. 4. The class size in this experiment was 52. 22 of these students scored in the A range. 16 students scored in the $\mathrm{B}$ range. The instructor saw strong correlation between regular attendance of the inclass session and a good final score in this class.

\section{FEEDBACK AND SUGGESTIONS}

At the time of writing of this paper, the official course evaluation, which can be taken as a representative of the students' impression of the course, was not yet available. However, based on informal feedback collected from the students, it can be seen that some of the students liked the experiment while others were struggling with it. One of the students posted on the website RateMyProfessor only after one month from the course start saying

"This guy made the course impossible. He tries to be edgy by replacing the lectures with YouTube videos, but all what really happened is that we do not learn anything. He also introduced labs and projects, something that no other 3-units course has. This makes you spend so much time on the course you will forget about anything else. Avoid him"

This strong reaction was noticed by the author in other educational experiments that were overall very successful. Some of the students simply find it difficult to adapt to the blended learning approach and they would prefer a traditional 
approach. Others find the laboratory experiments and the project pose more load on them and they do not see the great benefits these experiential tools bring.

Many students, on the other hand, wrote unsolicited emails expressing their full support of the approach. For example, one student wrote at the end of the course:

"It was an absolute pleasure having you as our professor for the term. Your interest for the subject shows through in every tutorial and is inspirational in helping every student learn. I also loved your method of online lecturing and will be sure to give great reviews of you in teacher evaluations."

Similar to criticism raised earlier against this approach, the main concern raised by several students was the timeconstraint. Many students complained that by watching the videos at home and then coming to the classroom, the time for lectures has effectively been doubled. This alone, given the busy schedule they have, have strained them. The author addressed this issue by eliminating some lecture sessions and replacing them with office hours thus giving the students more free time to study the material or ask questions about it.

\section{ACKNOWLEDGMENT}

The author would like to thank the Faculty of Engineering and the Department of Electrical and Computer Engineering for their support and encouragement through this experiment. Thanks are also due to all the students of my ENG 3N03 in 2015 who were part of this experiment.

\section{REFERENCES}

[1] B. Ives and K. Obenchain "Experiential learning and academic outcomes: for those who want it all," Journal of Experiential Education, vol. 29, pp. 61-77, 2006.

[2] F. Sana, B. Fenesi, and J. Kim, "A case study of the introductory psychology blended learning model at McMaster University," The Canadian Journal for the Scolarship of Teaching and Learning, vol. 2, Article 6, 2011.

[3] T.L. Floyd, Electronic Devices (Electron Flow Version), 9th Edition

[4] Multisim Student Edition, http://www.studica.com/multisim-studentedition.html.

[5] M.H. Bakr, "Teaching electromagnetics through a combination of blended learning and experiential learning," International Conference on Engineering Education and Research (iCEER2014-McMaster), August 2014 